\title{
Traumatic work related fatalities in commercial fishermen in Australia
}

Timothy R Driscoll, Guncha Ansari, James E Harrison, Michael S Frommer, Elizabeth A Ruck

\begin{abstract}
Objectives-To describe the types and circumstances of traumatic work related fatalities in Australian commercial fishermen.

Methods-Work related traumatic fishing fatalities were studied as part of a larger study of all work related traumatic fatalities in Australia from 1982 to 1984. Data on 47 cases were obtained from inspection of coroners' files.

Results-The incidence of fatality of $143 / 100000$ person-years was 18 times higher than the incidence of fatality for the entire workforce, and considerably higher than that of the mining and agricultural workforces. $68 \%$ of decedents drowned and $13 \%$ died from physical trauma. Rough weather, non-seaworthy vessels, inadequate use of personal flotation devices, and inexperience were associated with many of the fatal incidents. Discussion-Improved vessel and equipment maintenance, better training of workers, greater use of personal flotation devices, and development of improved clothing and personal flotation devices are recommended.
\end{abstract}

(Occup Environ Med 1994;51:612-616)

Keywords: occupational fatalities, fishing, drowning

National Institute of Occupational Health and Safety, Worksafe Australia, GPO Box 58, Sydney, NSW 2001, Australia

T R Driscoll

G Ansari

E A Ruck

National Injury

Surveillance Unit,

Australian Institute of

Health, Mark

Oliphant Building

Lafier Drive, Bedford

Park SA 5042,

Australia

J E Harrison

Epidemiology and Health Services

Evaluation Branch, NSW Health

Department, North Sydney, Australia M S Frommer

Correspondence to: Dr T R Driscoll, Epidemiology and Surveillance Unit, NIOHS (Worksafe Australia), GPO Box 58, Sydney, NSW 2001, Australia.

Accepted 16 May 1994
Ocean, where cold temperatures and high seas are common. The aim of this paper is to describe the types and circumstances of traumatic work related fatalities among commercial fishermen in Australia.

\section{Materials and methods}

Traumatic fatalities related to commercial fishing were studied as part of a larger investigation of deaths attributable to work related injury that occurred in Australia during the three calendar years 1982, 1983, and 1984 . The study method, which has been described in detail elsewhere, is outlined. ${ }^{15}$

A list was obtained of all deaths that occurred in the study period and that had been assigned International Classification of Diseases, revision 9 (ICD9) codes corresponding to external causes of death, excluding only suicide and medical misadventure. The list contained 16246 cases. Coroners' files were found for $15462(95 \cdot 2 \%)$ of these cases. Research officers examined the files and assessed which of the deaths met the study definitions of work related fatalities. Data were extracted from the files for these cases, recorded in data forms, and subsequently entered into a database for analysis. Of the 1738 cases that were classed as work related, 1544 were deaths of persons in the employed civilian labour force as defined by the Australian Bureau of Statistics. ${ }^{16}$ These deaths comprised 910 that occurred in the workplace, 368 that occurred on the road while working, and 266 that occurred on the road during journeys to and from work.

The employed civilian labour force included persons who worked for pay, profit, payment in kind, in a job, business, or on a farm (including employees, employers, and self employed people), and people who worked for $\geqslant 15 \mathrm{~h} /$ week without pay in a family business or on a farm. It was assembled, as far as possible, to correspond to the population that was covered by the Australian Bureau of Statistics labour force survey, ${ }^{16}$ and thus excluded people who were aged $<15$ or who were members of the armed forces. This definition is very similar to that used for the employed civilian labour force in the United States. ${ }^{17}$ The denominator used was the mean of the 12 employed civilian labour force surveys undertaken during the three years of the study. The population of commercial fishermen estimated from the surveys varied from 9425 to 12041 during the study period, with 
annual means of 10835 (1982), 10920 (1983), and 11189 (1984).

Deaths related to fishing were defined as those persons who had a fatal injury in the course of work and whose job at the time of injury involved fishing. This included persons involved in fish hatcheries but not process workers or distributors. Cases extracted from the main data set were those which, according to study codes, involved a person whose job at the time of injury involved fishing (codes 334 or 335 of "A classification and classified list of occupations"). ${ }^{18}$ Also, a computerised search of the text describing the circumstances of the fatal injury for all subjects was made, with keywords that suggested that the subject may have been involved in fishing at the time of injury-for example, drowned, water, fishing, trawler, etc. The complete study records of these cases were then inspected to make a final determination on which cases satisfied the study definition. Forty seven subjects formed the final data set. version 6.03. ${ }^{19}$ Confidence intervals (CIs) were calculated with the Poisson distribution, ${ }^{20}$ but they do not take into account the sample variance associated with the 12 employed civilian labour force surveys. The resultant CIs are therefore narrower than the true CIs.

\section{Results}

There were 47 traumatic fatalities among persons in the employed civilian labour force with fishing occupations in the three years 1982 to 1984 . This represented an incidence of $143 / 100000$ person-years (95\% CI: $105-$ 190). All but two of the decedents were male. The average age was 37 (SD 14.7), with 10 of the decedents $<25$ (table 1 ). The 47 fatalities arose from 38 incidents. There were nine instances of multiple fatalities, although in two of these the other deaths were not of someone engaged in fishing as part of their work at the time (two passengers in one case; one harbour master in the other). Of the remaining seven instances of multiple fatalities, two involved three deaths and five involved two deaths. Twenty of the fatal incidents $(42 \%)$ had at least one survivor.

Most decedents were working on trawlers (prawn, deep sea, or cray) at the time of their fatal incident, with over a third being trawler deckhands. Five decedents were tending lobster or crayfish pots (one working on a trawler, one washed off rocks, and three in small vessels, table 2 ).

Two thirds of the subjects drowned or their

Table 1 Work related fishing fatalities in the employed civilian labour force by age of decedent

\begin{tabular}{lrr}
\hline Age $(y)$ & \multicolumn{2}{c}{ Frequency (\%) } \\
\hline $15-24$ & $10(21)$ \\
$25-34$ & $16(34)$ \\
$35-44$ & $5(11)$ \\
$45-54$ & $8(17)$ \\
$55-64$ & $5(11)$ \\
$65+$ & 3 & $(6)$ \\
Total & $47(100)$ \\
\hline
\end{tabular}
bodies were not recovered and they were presumed to have drowned. Of the six subjects who died from physical trauma, two had head injuries (one struck by a falling pulley; one struck by a falling dock crane); two became entangled in equipment (one had clothing caught in a compressor; one became caught in a winch) and two died in motor vehicle accidents (one picking up equipment; one commuting). Sharks were responsible for the
Data were analysed with the SAS System,

Table 2 Work related fishing fatalities in the employed civilian labour force by occupation at the time of injury

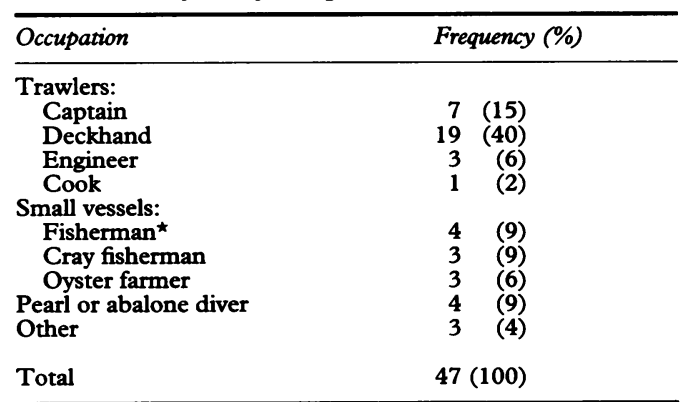

^Includes one person on an inland lake.

deaths of at least two, and possibly three, subjects (table 3).

Rough or bad weather was an important contributory cause of 25 of the fatalities (including one of the motor vehicle accidents). In most of these cases the vessel capsised or sank with little or no warning, generally without time to adequately release flotation support equipment and often without time to send out a distress call. Three decedents fell overboard and drowned, five subjects died while diving, and the remainder of the cases died in a variety of circumstances. These included five decedents whose fatal incident occurred on shore or when the vessel was docked, and one who drowned on an inland lake during bad weather (table 4).

Lack of sea worthiness was an important direct contributory factor in the fatal incident in five cases, with a further three deaths associated with a lack of sea worthiness in life rafts. Equipment failure (broken boom; broken pulley; failed autopilot) was directly associated with the fatal incident in four cases. In four other cases equipment failure may have

Table 3 Work related fishing fatalities in the employed civilian labour force by cause of death

\begin{tabular}{lc}
\hline Cause & Frequency (\%) \\
\hline Drowned & $17(36)$ \\
Presumed drowned & $15(32)$ \\
Mechanical trauma & $6(13)$ \\
Barotrauma & $3(6)$ \\
Electrocution & $2(4)$ \\
Shark attack & $2(4)$ \\
Smoke inhalation & $1(2)$ \\
Uncertain & $1(2)$ \\
Total & $47(99)^{\star}$
\end{tabular}

^Percentages do not add up to 100 because of rounding.

Table 4 Work related fishing fatalities in the employed civilian labour force by circumstance of incident

\begin{tabular}{llll}
\hline & \multicolumn{2}{l}{ Bad weather } & Good weather Total \\
\hline Boat lost or disabled: & & & \\
$\quad$ Capsised or sunk & 23 & 3 & 26 \\
$\quad$ Run onto rocks & 1 & 2 & 3 \\
Diving & - & 5 & 5 \\
Fell overboard & - & 3 & 3 \\
Maintenance & - & 2 & 2 \\
Hauling in nets & - & 1 & 2 \\
Motor vehicle accident & 1 & 4 & 4 \\
Other & - & 22 & 47 \\
Total & 25 & &
\end{tabular}


Table 5 Work related fishing fatalities: comparison of results from different countries

\begin{tabular}{|c|c|c|c|c|c|c|}
\hline $\begin{array}{l}\text { Country } \\
\text { Period (calendar years) }\end{array}$ & $\begin{array}{l}\text { Australia } \\
82-84\end{array}$ & $\begin{array}{l}\text { Alaskat } \\
91-92\end{array}$ & $\begin{array}{l}\text { Canada } \\
75-83\end{array}$ & $\begin{array}{l}\text { Iceland } \\
66-86\end{array}$ & $\begin{array}{l}\text { New Zealand } \\
75-84\end{array}$ & $\begin{array}{l}U K \| \\
61-80\end{array}$ \\
\hline $\begin{array}{l}\text { No } \\
\text { Incidence of fatality (/100 } 000 \text { person-years) } \\
\text { Drowning (\%) } \\
\text { On shore deaths (\%) } \\
\text { Due to bad weather (\%) } \\
\text { Due to loss or disablement (\%) } \\
\text { Washed overboard (\%) }\end{array}$ & $\begin{array}{r}47 \\
143 \\
68 \\
13 \\
53 \\
62 \\
6\end{array}$ & $\begin{array}{r}70 \\
200 \\
94 \\
0 \\
? \\
77 \\
23\end{array}$ & $\begin{array}{l}98 \\
53 \\
93^{\star \star} \\
12 \\
? \\
? \\
?\end{array}$ & $\begin{array}{c}132 \\
89 \\
85 \\
0++ \\
? \\
? \\
?\end{array}$ & $\begin{array}{r}75 \\
260 \\
90 \\
6 \\
61 \\
78 \\
13\end{array}$ & $\begin{array}{c}711 \\
170 \\
68^{\star \star} \\
0+\dagger \\
? \\
71 \\
34 \neq \ddagger\end{array}$ \\
\hline
\end{tabular}

*Current study.

†MMWR, 1993'12: denominator based on vessel landings and associated crew size.

† Hasselback and Neutel, $1990^{8}$ : denominator based on time from first registration for persons with a commercial fishing licence.

$\oint$ Rafnsson and Gunnarsdottir, $1992^{10}$ : denominator based on persons registered in seamen's pension fund.

TNorrish and Cryer, $1990^{\circ}$ : denominator estimated with data from national censuses.

Reilly, $1985^{7}$ : denominator based on number of registered fishermen.

$\star \star$ Estimated from paper.

HOn shore deaths excluded.

\#Data only available for deep sea deaths.

contributed to the fatal incident. Of the remaining 31 cases, the vessel was known to be sea worthy in 12 cases and there was no recorded equipment failure in the other 19. Three deaths from the one incident occurred when a trawler, heavily overloaded with fish, capsised in rough weather.

In 14 cases the use of flotation support equipment (life jackets or life rafts) would not have contributed to the subject surviving the fatal incident. The other 33 cases drowned or were taken by sharks. Of these subjects 25 (some of whom were poor swimmers) were not wearing any flotation device, three had life jackets on at least some of the time but still eventually drowned, and in five cases the body was not recovered and there was no information on flotation devices. The circumstances of six of these deaths suggest that there was probably ample time to put on a life jacket between when the vessel began to sink and when the subject entered the water, but the jackets were either not available (three) or possibly available but not used (three). In most cases, however, there would not have been adequate warning, apart from rough weather, to enable a life jacket to be put on once the vessel began to founder.

The number of years working in the job in which the decedent was working at the time of death was known for only 22 of the cases. Of these, eight (36\%) had worked in the job for $<1$ year and $15(68 \%)$ for $<3$ years. In five of the deaths lack of experience was directly implicated by the coronial investigation as being a main cause of the fatality.

\section{Discussion}

The incidence of fatalities of $143 / 100000$ person-years for persons working in fishing occupations is one of the highest of any occupation in Australia. It compares with incidences (/100 000 person-years) of $8 \cdot 1$ for the whole employed civilian labour force, 70 for mining and quarrying, and 19 for agriculture. ${ }^{1521}$ The main overseas studies of commercial fishing traumatic fatalities are from Alaska, ${ }^{12}$ Canada, ${ }^{8}$ Iceland, ${ }^{10}$ New Zealand, and the United Kingdom. ${ }^{7}$ Several other studies investigating or reviewing fatalities or injuries have also been published. ${ }^{22-24}$ Comparisons between these studies and ours should be made with reservations because the studies had slightly different inclusion criteria for the numerator and the denominator. Such comparisons serve to highlight the hazards and risks that Australian commercial fishermen have, and do not have, in common with other countries (table 5).

As in most other studies of fishing fatalities, the primary cause of death was drowning. In this study $32 \%$ of decedents died from other causes, including contact with electricity, an almost ubiquitous workplace hazard. ${ }^{25}$ The proportion of deaths due to drowning was higher in Alaska, Canada, and Iceland, and similar in the United Kingdom and New Zealand. The extent of inclusion of on shore deaths obviously affects these figures. In this study $13 \%$ of the deaths occurred on shore or while the vessel was docked. The other studies where on shore deaths were included had similar or smaller proportions of on shore deaths. Whether to include motor vehicle accidents in a study of commercial fishing fatalities is a matter for debate. They were included in this study because one accident occurred specifically as part of the decedent's duties as a deckhand, and the other occurred while the decedent was returning home from work and therefore was still covered by workers' compensation according to Australian law then in force.

Bad weather was the primary cause of the fatal event in $53 \%$ of cases, compared with $61 \%$ in New Zealand ${ }^{9}$ and an unknown proportion of cases in other studies. Vessel loss or disablement, either due to sinking, capsising, or collision with rocks, resulted in $29(62 \%)$ deaths in this study. Although this was the main cause of fatal events, $47 \%$ of cases were not associated with bad weather conditions, indicating that there are other important hazards faced by fishermen.

The $26 \%$ of deaths directly attributable to lack of sea worthiness or equipment failure highlights the need for vigilance in maintaining vessels, general equipment and safety apparatus. The lack of use of flotation support apparatus in the fatal incidents was considerable. Use of personal flotation devices has been associated with increased likelihood of survival in fatal incidents that have at least one survivor. ${ }^{12}$ There was insufficient information available in this study to properly 
investigate this association. In the $42 \%$ of fatal incidents in this study that had at least one survivor, those persons who did survive seem to have done so because they were able to obtain some form of flotation support in the form of life rafts, life jackets, or debris. Only three people who died in circumstances in which personal flotation devices would have been of help wore a life jacket at some stage during the fatal event. These results suggest that after vessel loss or disablement, even in isolated areas of deep water, survival is possible and would be enhanced by the use of personal flotation devices. Unfortunately, the vessel loss or disablement happened so rapidly in most of the incidents in this study that there would have been very little time to put on a life jacket or launch a life raft once it became clear that the vessel was at grave risk. Rough weather was therefore the only early warning of increased risk in these cases. Regular use of life jackets in bad weather is complicated by the fact that most life jackets as currently designed may interfere with efficient on board work and may place the worker at greater risk of on board injury. ${ }^{26}$ Nevertheless, about half the people in this study died because, in part at least, they entered the water without adequate flotation support. It is therefore important to have flotation devices placed near work stations-for example, the wheel house-for ready access in an emergency, and to encourage use of the newer inflatable life jackets, which may be suitable for use during normal work when worn while uninflated.

Water temperature and type of clothing worn are other important factors in incident survival after entering the water. The typical cold weather clothing of long tunic and thigh length boots was identified as a main contributory factor to three of the deaths by drowning. The negative buoyancy of such clothing has been identified before. ${ }^{27}$ The need for thermal protection has been identified in northern hemisphere studies. ${ }^{712}$ In Australia this is less of a problem in the warmer northern fishing areas, but is very important in the southern deep sea fishing areas. The lower proportion of deaths from falling overboard in Australia (and to a lesser extent in New Zealand) compared with the northern hemisphere studies is probably a reflection of the warmer water temperatures around much of the Australian coastline, allowing survival in the water for a longer period before the onset of profound hypothermia. Hypothermia probably contributed to a small proportion of deaths in this study, but available information did not allow a precise determination of the role of hypothermia in all cases. The need for the development of flexible, durable, and buoyant clothing, and personal flotation devices that can be worn for prolonged periods of bad weather and that have only minimal interference with working activities, has been noted in other studies. ${ }^{1712}$ The findings from this study suggest that this remains a priority.

Inexperience was a feature of a considerable number of the decedents. Many fishermen, especially those working on trawlers, change job frequently. ${ }^{4}$ Precise information on job experience in the fishing workforce was not available, making it difficult to adequately determine the contribution of lack of experience to risk of fatal injury. Eleven percent of the deaths (including two of the five diving deaths) were directly linked to lack of experience. With no formal training required in what remains an essentially heavy, labour intensive, high risk occupation, inexperience must remain a major concern. Currently, training generally takes the form of on the job experience. Most formal instruction is conducted by the Fishing Industry Training Councils, but this tends to concentrate on technical training rather than on health and safety aspects.

Changes in technology in the fishing industry over the last decade may be expected to have decreased the risk to fishermen. Alternatively, there may be areas of increased risk. This is because some technology (such as global positioning equipment and autopilot) reduces hands on requirements, which presumably can lead to decreased vigilance, and also allows more movement at night, possibly increasing the risks of collision. Studies in the northern hemisphere have found no improvement in incidence of fatalities despite efforts aimed at improving safety. ${ }^{710}$ More recent Australian data would provide a useful comparison to the data in this study.

One of the main shortcomings identified in some other studies of commercial fishermen has been incomplete case ascertainment ${ }^{78}$ and uncertainty regarding denominators. ${ }^{7-1012}$ The coronial system in Australia covers all traumatic or unusual deaths and the overall study identified $95 \%$ of the initial coronial files to be searched. Of the 784 missing cases, 399 (51\%) were elderly people who died as a result of a fall, the circumstances of which did not warrant a coronial inquest. The remaining 385 cases $(2 \cdot 4 \%$ of the total) were missing for a variety of reasons (in use by courts; lost; could not be found) not likely to be specifically associated with work related deaths in general nor fishing in particular. Given that there were 47 cases of work related deaths in fishermen found from inspection of 15462 files $(0.3 \%)$, there is likely to be no more than one further such case in the missing 385 files. This, combined with the comprehensive file search procedures, should have ensured that virtually all relevant deaths were identified for this study. As the case file data were extracted for a study of all work related traumatic fatalities, information was not collected specifically to investigate all factors relevant to fishing fatalities. Nevertheless, detailed information was available for most cases. Denominators were obtained from labour force surveys conducted during the same period as the numerator data were obtained. The low numbers employed in the fishing occupations in the labour force necessarily introduces a degree of error into the denominator, as the data were obtained with a sampling procedure. Data from the 1981 or 1986 national censuses were not thought to be appropriate because they 
represent a single data collection period in winter, and therefore miss many of the summer seasonal workers and probably some of those away at sea on the day of collection. Rates calculated with census data in the denominator would therefore be expected to be artificially high.

The data in this study were insufficient to allow detailed investigation of factors such as the length of time the vessel had been at sea, the size of the crew, the experience of crew members, the contribution of safety equipment to subject survival, the type of clothing being worn at the time of the incident, and the role of hypothermia. Further studies considering these areas would be of use, and collection of such information by investigating authorities should be encouraged.

This study is the first detailed study of work related traumatic fatalities in commercial fishermen in Australia and has shown fishing to be a high risk occupation in this country, as it is in many others. Efforts directed towards vessel and equipment maintenance and training of inexperienced workers; more widespread use of and easy access to personal flotation devices; and development of improved work clothing and personal flotation devices are likely to improve the safety of commercial fishermen.

We wish to thank Mr Frank Prokop for his helpful comment and suggestions regarding the manuscript.

The views expressed in this article are those of the authors and do not necessarily reflect those of the National Occupational Health and Safety Commission.

1 Holland Martin D. Trawler safety-final report of the committee of inquiry into trawler safety. London: HMSO, mittee 1969.

2 Schilling RSF. Hazards of deep-sea fishing. $\mathrm{Br} \mathcal{F}$ Ind $\mathrm{Med}$ 1971;28:27-35.

3 Barss PG. Penetrating wounds caused by needle-fish in Oceania. Med $\mathfrak{f}$ Aust 1985;143:617-22.

4 Jeays LW. Safety for fisherman on trawlers. Sydney: National Occupational Health and Safety Commission, 1987.

5 Dutkiewicz J, Jablonski L, Olenchock SA. Occupationa biohazards: a review. Am f Ind Med 1988;14:605-23.
6 Sutherland KM, Flin RH. Stress at sea: a review of working conditions in the offshore oil and fishing industries. Work and Stress 1989;3:269-85.

7 Reilly MSJ. Mortality from occupational accidents to United Kingdom fishermen 1961-80. Br $\mathcal{F}$ Ind Med 1985;42:806-14.

8 Hasselback P, Neutel CI. Risk for commercial fishing deaths in Canadian Atlantic provinces. $\mathrm{Br} F$ Ind Med deaths in Canadian

9 Norrish AE, Cryer PC. Work-related injury in New Zealand commercial fishermen. Br F Ind Med 1990;47: 726-32.

10 Rafnsson V, Gunnarsdottir H. Fatal accidents among Icelandic seamen: $1966-86 . \mathrm{Br} \mathcal{F}$ Ind Med 1992;49. 694-9.

11 Schnitzer PG, Bender TR. Surveillance of traumatic occupational fatalities in Alaska-implications for prevention. Public Health Rep 1992;107:70-4.

12 Commercial fishing fatalities-Alaska, 1991-1992 MMWR Morb Morral Wkly Rep 1993;42:350-1,357-9.

13 Australian Bureau of Statistics (ABS). Yearbook Australia 1994. Canberra: ABS, 1993. (Catalogue No 1301.0.)

14 Australian Bureau of Statistics (ABS). The labour force, Australia: 1978 to 1989 Canberra: ABS, 1992. (Catalogue no 6204.0.)

15 Harrison JE, Frommer MS, Ruck EA, Blyth FM. Death as a result of work-related injury in Australia, 1982-1984. Med $\mathcal{F}$ Aust 1989;150:118-25.

16 Australian Bureau of Statistics (ABS). A guide to labour statistics. Canberra: ABS, 1986. (Catalogue no 6102.0.)

17 United States Bureau of the Census (USBC). Statistical abstracts of the US, 11th ed. Washington DC: USBC 1991.

18 Australian Bureau of Statistics (ABS). A classification and classified list of occupations. Canberra: ABS, 1981. (Cataclassified list of occupa

19 SAS Institute. SAS System, version 6.03. Cary, NC: SAS Institute, 1987.

20 Armitage $\mathrm{P}$, Berry G. Statistical methods in medical research, 2nd ed. Trowbridge: Blackwell Sci Publ, 1988.

21 Erlich SM, Driscoll TR, Harrison JE, Frommer MS, Leigh J. Work-related agricultural fatalities in Australia 1982-1984. Scand $f$ Work Environ Health 1993;19: $162-7$

22 Cadenhead R McN. Hospital admissions of fishermen from the fishing grounds around the Shetland Islands. fournal of the Society of Occupational Medicine 1976;26: 127-31.

23 Cross T. The health of British trawlermen on the Arctic fishing grounds. Fournal of the Society of Occupational Medicine 1985;35:55-61.

24 Moore SRW. The mortality and morbidity of deep sea fishermen sailing from Grimsby in one year. $B r f$ Ind fishermen sailing from

25 Harvey-Sutton PL, Driscoll TR, Frommer MS, Harrison JE. Work-related electrical fatalities in Australia 1982-1984. Scand $\mathcal{f}$ Work Environ Health 1992;18 293-7.

26 Coast Guard, US Department of Transportation Commercial fishing industry vessel regulations: final rule. Federal Register 1991;56:40367-8. Cited in Commercial fishing fatalities-Alaska, 1991-1992. MMWR Morb Mortal Wkly Rep 1993;42:350-1, 357-9.12

27 Crockford GW. Buoyancy suits for fishermen Occupational Health 1973;25:288-95. 